\title{
Molecular docking of Subtilisin K2, a fibrin-degrading enzyme from Indonesian moromi, with its substrates
}

\author{
Fathma SYAHBANU ${ }^{1}$ (D), Puspo Edi GIRIWONO ${ }^{1}$, Raymond R. TJANDRAWINATA ${ }^{2}$ (D), \\ Maggy T. SUHARTONO ${ }^{1 \star}$ (i)
}

\begin{abstract}
Fibrinogen supplies the primary building block of the blood clot or thrombus after $\alpha$-thrombin converts fibrinogen to fibrin during the final phases of coagulation. When the homeostasis system is disrupted, blood clots that aggregate in the blood vessels can lead to thrombosis. Fibrin-degrading enzyme from Bacillus subtilis K2 (Subtilisin K2) of Indonesian moromi has many excellent characteristics apart from its strong fibrinolytic activity. Bioinformatic analysis using the CDART webserver indicated that the enzyme appeared to share a conserved domain with the peptidase s8 superfamily also known as the subtilase family. This study used molecular docking between these fibrin-degrading enzymes and specific substrates (fibrin and fibrinogen) using the HADDOCK webserver and aimed to predict the enzyme mechanism of action. This analysis revealed that the enzyme interlocked with the two substrates; however, it suggested no productive interactions between Subtilisin K2 and fibrinogen. A hydrolysis reaction is suggested between Subtilisin K2 and the fibrin substrate. There was a strong indication that amino acids Asp19, His51, and Ser208 in Subtilisin K2's active site interacts with Leu168, Ile171, and Leu172 of the fibrin substrate with a $\Delta \mathrm{G}$ of $-19.4 \mathrm{kcal} / \mathrm{mol}$. Subtilisin $\mathrm{K} 2$ tends to act more as a fibrin-degrading enzyme than as a fibrinogen-degrading enzyme.
\end{abstract}

Keywords: binding affinity; domain; fibrinogen; fibrin; molecular docking.

Practical Application: Our study on finding fibrin and fibrinogen degrading enzyme from bacteria isolated from Indonesian fermented food (Moromi) supported by bioinformatic analysis which reveal more important information of the suitable enzyme characteristics for health applications is useful for remedy of thrombosis healing.

\section{Introduction}

Fibrinogen and fibrin show overlapping important roles in wound healing, blood clotting, fibrinolysis, neoplasia, cellular and matrix interactions, and the inflammatory response. Interactive sites on fibrinogen and fibrin adjust these functions, some of which are concealed or otherwise not available on fibrinogen, and they frequently evolve as a consequence of fibrin formation or fibrinogen-surface interactions (La Corte et al., 2011). Fibrinogen is a widely available plasma protein. Fibrinogen provides the primary building blocks of thrombi during the final phases of coagulation, when $\alpha$-thrombin converts fibrinogen into a fibrin clot. Increased concentrations of fibrinogen in the blood have been related to the risk for thrombosis. In recent decades, there have been many related studies on abnormal fibrin structure as one of the causes of thrombosis. The high fiber density of fibrin clots and increased resistance to fibrinolysis have been consistently related to the risk for thrombosis (Hill \& Dolan, 2008; De Moerloose et al., 2010; Bornikova et al., 2011; Ariëns, 2013).

Fibrinogen harbors some structural domains with different functions. The domain that contains the cleavage sites for thrombin, the central $\mathrm{E}$ domain, is connected to two $\mathrm{D}$ domains consisting of binding pockets for polymerization by two coiled coil domains that provide elasticity to this molecule (Yang et al., 2000). The A $\alpha$-chain protrudes from the D domain and forms the flexible $\alpha \mathrm{C}$ domain, whereas the $\mathrm{B} \beta$ - and $\gamma$-chains end in the D domain (Tsurupa et al., 2009). Thrombin converts fibrinogen into fibrin through the cleavage of two fibrinopeptides A from the A $\alpha$ chain (16 residues) and two fibrinopeptides $B$ from the B $\beta$ chain (14 residues) (Yang et al., 2000; La Corte et al., 2011). Fibrinopeptide A is cleaved first and exposes the Gly-Pro-Arg (GPR) binding site on the E domain of fibrin for attaching to the binding pocket in the $\mathrm{D}$ domain. This interaction causes the binding of several fibrin molecules, which results in the formation of fibrin polymer, also called the protofibril, which consists of half-staggered, overlapping fibrin molecules (Figure 1).

Fibrin also shows three main chains in its structure, namely, the $\alpha$-, $\beta$-, and $\gamma$-chains. The fibrin $\alpha$ chain plays a role in clot formation and accelerates polymerization of the clot structure (Gorkun et al., 1994). Molecular and cellular interactions take place on the fibrin $\beta$ chain in residues 15-42. Fibrin $\beta-15-42$ binds to heparin and mediates platelet and endothelial cell spreading, fibroblast proliferation, and capillary tube formation. Interactions between vascular endothelial (VE)-cadherin (an endothelial cell receptor) and fibrin $\beta 15-42$ promote capillary tube formation and angiogenesis (Mosesson, 2005).

Our earlier work has shown that the Subtilisin K2 enzyme of Indonesian moromi is capable of hydrolyzing fibrin, as shown

${ }^{1}$ Department of Food Science and Technology, IPB University (Bogor Agricultural University), Dramaga, Bogor, Indonesia

${ }^{2}$ Dexa Laboratories of Biomolecular Sciences, Dexa Medica Jababeka, Cikarang, Indonesia

*Corresponding author: mthenawidjaja@yahoo.com 


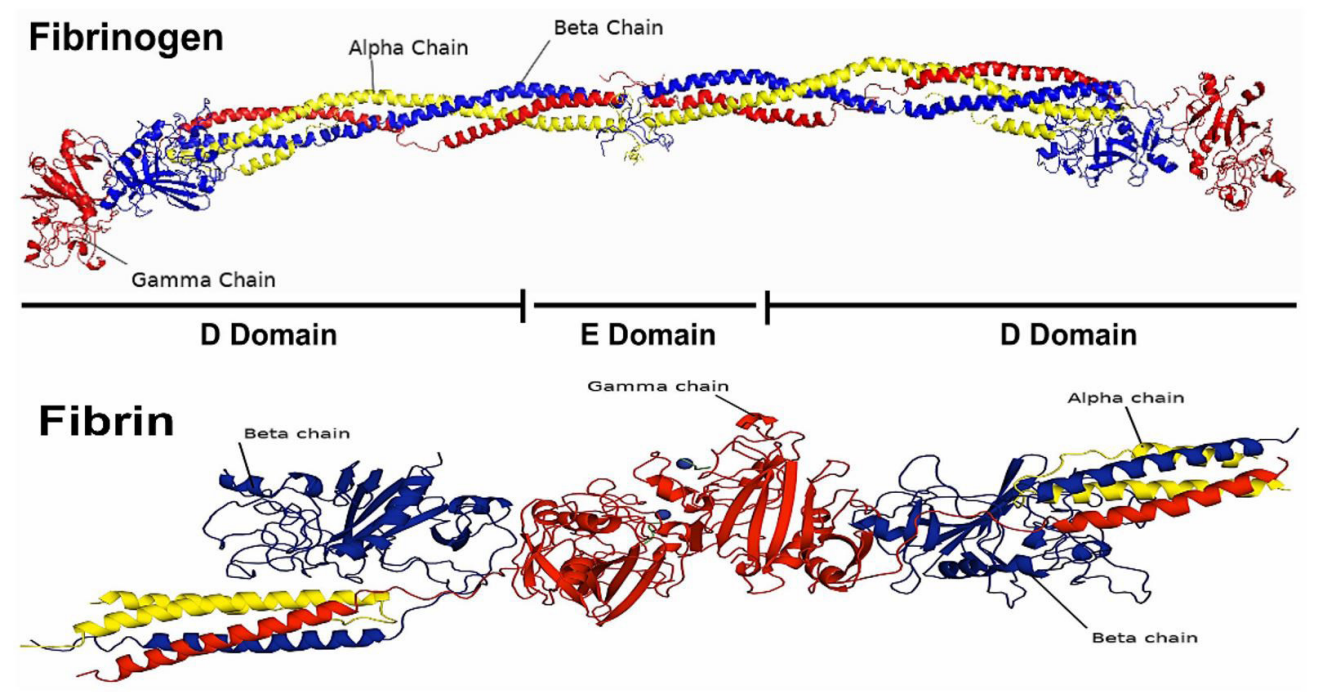

Figure 1. Fibrinogen and fibrin structures.

by the fibrin plate assay (Syahbanu et al., 2020a), as well as hydrolyzing fibrinogen in fibrinogen zymogram analysis (Syahbanu et al., 2020b). The present bioinformatic work was carried out to elucidate in more detail the mode of this interaction with the substrates fibrin and fibrinogen. This information will be useful and used as the basis for further strategies in drug development for diseases related to thrombosis and atherothrombosis such as CVD. The three-dimensional model of the Subtilisin K2 protease from Bacillus subtilis K2 was developed by using the SWISS-MODEL Workspace (Schwede et al., 2003; Arnold et al., 2006; Benkert et al., 2011; Biasini et al., 2014). Our previous study revealed that Subtilisin K2 possesses active site residues Asp19, His51, and Ser208, which are typical of the serine protease family (Syahbanu et al., 2020b). Preliminary bioinformatic analysis suggested that Subtilisin K2 interacts with Leu168, Ile171, and Leu172 of fibrin substrates with high binding affinity $(\Delta \mathrm{G}=-19.4 \mathrm{kcal} / \mathrm{mol}$ ) (Syahbanu et al., 2020b). In this study, we further analyzed the interactions that occur between the enzyme and several domains of the fibrin substrate and fibrinogen substrate.

\section{Materials and methods}

\subsection{Materials}

The protein sequence of the fibrin-degrading enzyme Subtilisin K2 from Bacillus subtilis K2 (this isolate originated from moromi and was previously collected (Syahbanu et al., 2020a)) was retrieved from GenBank (accession number: MN294987). Subtilisin K2 consists of 262 amino acids, and the sequence data were saved in the FASTA format. The 3D structure of Subtilisin $\mathrm{K} 2$ was constructed using the SWISS-MODEL Workspace (Swiss Institute of Bioinformatics, 2020) program (RRID:SCR_018123) (Schwede et al., 2003; Arnold et al., 2006; Benkert et al., 2011; Biasini et al., 2014) as reported by Syahbanu et al. (2020b). The fibrin and fibrinogen structures were retrieved from RCSB PDB (PDB IDs: 2HLO (fibrin) and 3GHG (fibrinogen)) as receptors for the molecular docking experiments with Subtilisin K2 as a ligand.

\subsection{Prediction of motifs and conserve domain}

The presence of motif seequence in Subtilisin K2 protease was assessed by MyHits (2020; Sigrist et al., 2010), and the conserved domain was predicted using the Conserved Domain Architecture Retrieval Tool (CDART) (National Center for Biotechnology Information, 2020; Geer et al., 2002).

\subsection{Molecular docking study}

Molecular docking was performed between the Subtilisin K2 model and either the fibrin or fibrinogen substrate. Docking analysis predicted the interaction site of Subtilisin K2 with fibrin and fibrinogen using the Consensus Prediction Of interface Residues in Transient complexes (CPORT) web server (Utrecht University, 2020a; De Vries \& Bonvin, 2011). This method is a physical and knowledge-based approach to predict the interactive or binding sites for protein interactions. The High Ambiguity Driven protein-protein DOCKing (HADDOCK) web server (Wassenaar et al., 2012; Van Zundert et al., 2016) was used to perform protein docking. The HADDOCK (High Ambiguity Driven protein-protein DOCKing) web server (Wassenaar et al., 2012; Van Zundert et al., 2016; Utrecht University, 2020b) use chemical shift perturbation data resulting from NMR titration experiments, mutagenesis data, and bioinformatics predictions. The 3D Subtilisin K2 structure was docked by a flexible docking method with fibrin and fibrinogen molecules retrieved from the Research Collaboratory for Structural Bioinformatics (RCSB) Protein Data Bank (Research Collaboratory for Structural Bioinformatics, 2020) using the HADDOCK web server (Wassenaar et al., 2012; Van Zundert et al., 2016). Prediction of the binding affinity in protein-protein complexes was performed using the Prodigy (Protein Binding Energy Prediction) web server (Vangone \& Bonvin, 2015; Xue et al., 2016; Computational Structural Biology Group, 2020). Calculation of the predictive value of the binding affinity $(\Delta \mathrm{G})$ and dissociation constant $(\mathrm{Kd})$ on the Prodigy web server was performed using the following Equation 1 (Vangone \& Bonvin, 2015; Xue et al., 2016): 
$\Delta G_{\text {predicted }}=-0.09459 \mathrm{ICs}_{\text {charged/charged }}-0.10007 \mathrm{ICs}_{\text {charged/apolar }}+$ 0.19577 ICs $_{\text {polar/polar }}-0.22671$ ICs $_{\text {polar/apolar }}+0.18681 \% N I S_{\text {apolar }}+$ $0.3810 \%$ NIS charged -15.9433

Based on the prediction of binding affinity ( $\Delta$ Gpredicted) according to the above equation, the dissociation constant $(\mathrm{Kd})$ was calculated using the following Formula 2 (Vangone \& Bonvin, 2015; Xue et al., 2016):

$\Delta G=R T \ln K d$

where $\mathrm{R}$ is the ideal gas constant (in $\mathrm{kcal} \mathrm{K}^{-1} \mathrm{~mol}^{-1}$ ), T is temperature (in $\mathrm{K}$ ) and $\Delta \mathrm{G}$ is the predicted free energy. In this study, the temperature was adjusted according to the normal human body temperature at $309.5 \mathrm{~K}\left(36.5^{\circ} \mathrm{C}\right)$. LigPlot+ Version v.2.1 (European Molecular Biology Laboratory, 2020; Wallace et al., 1995) was used to generate schematic diagrams of proteinprotein interactions.

\section{Results and discussion}

\subsection{Prediction of motif and conserved domain}

The prediction of the conserved domains in Subtilisin K2 was performed earlier through the CDART web server (Geer et al., 2002). In this study, analysis of the enzyme encoded by the fibrinolytic gene revealed a conserved domain shared with the peptidase 8 superfamily, which is also known as the subtilase family, the second largest family of serine peptidases, both in terms of the number of sequences and the characterized peptidases. Determination of the protein motif was also carried out earlier using the MyHits (2020) website (Sigrist et al., 2010).

Based on the results of the motif search, several short motifs were found in the Subtilisin K2: an Asp subtilase motif (VAVIDSGIDSsH), a His subtilase motif (HGTHVAGTIAA), a Ser subtilase motif(GTSMATPHVAG), an ASN_GLYCOSYLATION motif, a CK2_PHOSPHO_SITE motif, and MYRISTYL motif.

\subsection{Molecular docking analysis}

The fibrin structure consists of three chains, namely the a chains (domain A and domain D), $\beta$ chains (domain B and domain E), and $\gamma$ chains (domain C and domain F). Application of LigPlot+ provided information on the possible interactions occurring between enzymes and substrates through hydrogen bonds and hydrophobic interactions. The greater the formation of hydrogen bonds and hydrophobic interactions is, the better the interactions between enzymes and substrates. This bioinformatic study implies that domains $\mathrm{A}$ and $\mathrm{D}$ of the $\alpha$ chains of the fibrin molecule have favorable interactions with the enzyme (Figure 2).

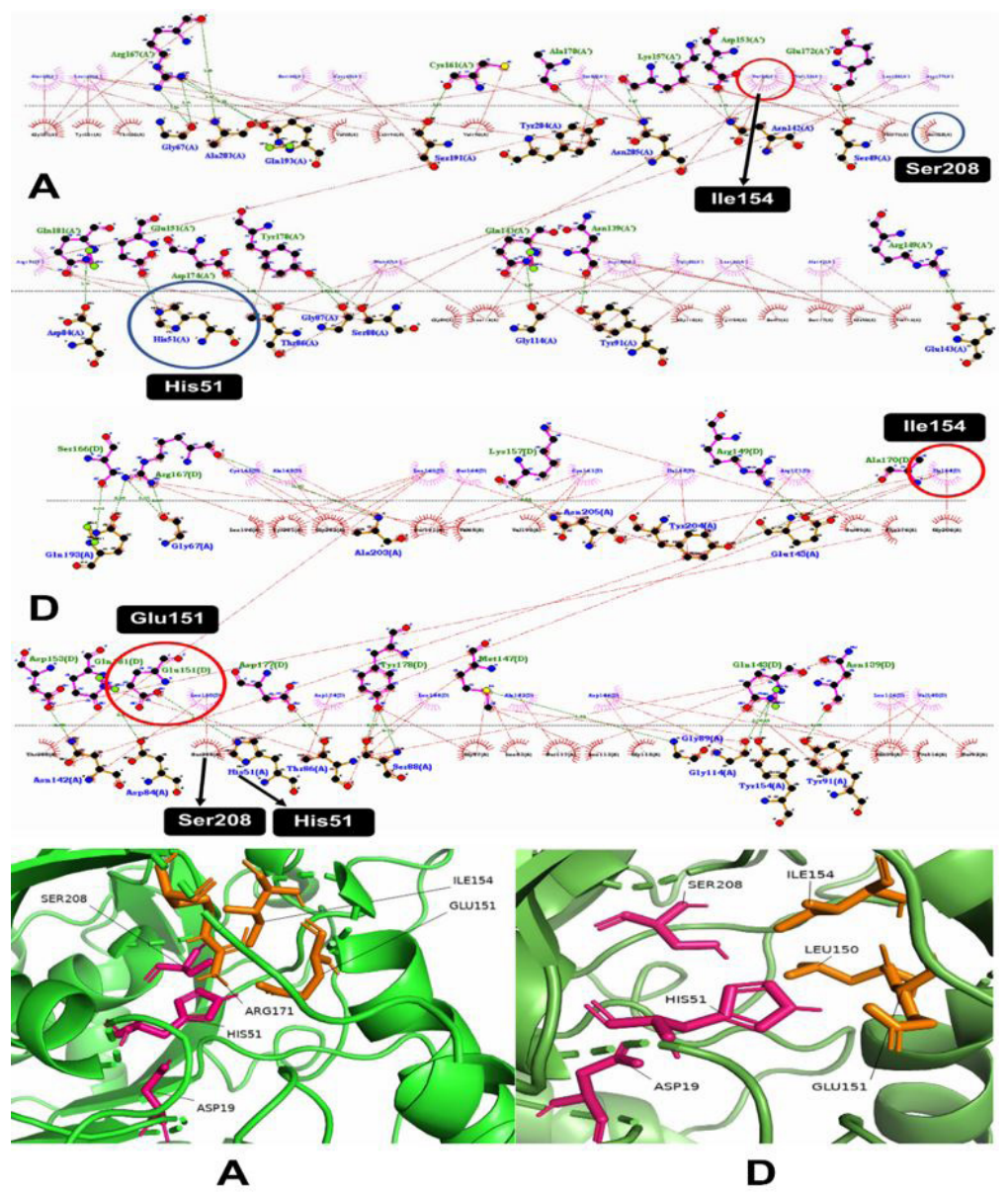

Figure 2. Interaction between the enzyme model with the alpha chain of fibrin (A and D domains) (blue circles and pink sticks = active site of the enzyme; red circles and orange sticks = substrate specificity of fibrin). 
The results from Prodigy (Vangone \& Bonvin, 2015; Xue et al., 2016) show a high binding affinity energy $(\Delta G)$ and low dissociation constant $(\mathrm{Kd})$ with the A domain $(\Delta \mathrm{G}=-14.9 \mathrm{kcal} / \mathrm{mol}$; $\mathrm{Kd}=1.1 \mathrm{E}-11 \mathrm{M})$ and $\mathrm{D}$ domain $(\Delta \mathrm{G}=-14.8 \mathrm{kcal} / \mathrm{mol}$; $\mathrm{Kd}=1.4 \mathrm{E}-11 \mathrm{M})$. The binding affinity energy of the A and $\mathrm{D}$ domains with the enzyme was higher than that of the $\mathrm{C}$ and $\mathrm{F}$ domains of fibrin, and the dissociation constant of the $\mathrm{A}$ and $\mathrm{D}$ domains with the enzyme was lower than that of the $\mathrm{C}$ and $\mathrm{F}$ domains of fibrin (Table 1).

Table 1. Results of docking the enzyme model with the substrates.

\begin{tabular}{cclc}
\hline $\begin{array}{c}\text { Chain-Domain } \\
\text { Fibrin }\end{array}$ & $\Delta \mathrm{G}\left(\mathrm{kcal} \mathrm{mol}^{-1}\right)$ & $\mathrm{Kd}(\mathrm{M})$ & $\mathrm{RMSD}(\AA)$ \\
\hline$\alpha \mathrm{A}$ & -14.9 & $1.1 \mathrm{E}-11$ & $0.7 \pm 0.5$ \\
$\alpha \mathrm{D}$ & -14.8 & $1.4 \mathrm{E}-11$ & $0.4 \pm 0.2$ \\
$\beta \mathrm{B}$ & -19.0 & $1.1 \mathrm{E}-14$ & $0.5 \pm 0.3$ \\
$\beta \mathrm{E}$ & -19.4 & $6.3 \mathrm{E}-15$ & $0.8 \pm 0.6$ \\
$\gamma \mathrm{C}$ & -13.9 & $6.5 \mathrm{E}-11$ & $0.5 \pm 0.3$ \\
$\gamma \mathrm{F}$ & -13.5 & $1.3 \mathrm{E}-10$ & $1.0 \pm 1.0$ \\
\hline Chain Fibrinogen & $\Delta \mathrm{G}\left(\mathrm{kcal} \mathrm{mol}^{-1}\right)$ & $\mathrm{Kd}(\mathrm{M})$ & $\mathrm{RMSD}(\AA)$ \\
\hline $\mathrm{A} \alpha$ & -10.4 & $2.2 \mathrm{E}-8$ & $0.7 \pm 0.5$ \\
$\mathrm{~B} \beta$ & -15.6 & $3.9 \mathrm{E}-12$ & $0.4 \pm 0.3$ \\
$\gamma$ & -15.2 & $6.7 \mathrm{E}-12$ & $0.4 \pm 0.2$ \\
\hline
\end{tabular}

Note: Kd = Dissociation Constant, RMSD = Root Mean Square Deviation.
The binding affinity (or binding free energy) $(\Delta \mathrm{G})$ represents whether complex formation takes place favorably under specific conditions (Kastritis et al., 2014). Binding affinity is the strength of the binding interaction between a single biological macromolecule (such as protein or DNA) to its ligand/binding partner (such as a protein, drug, or inhibitor). The more negative the binding free energy $(\Delta G)$ is, the stronger the interaction/binding between the receptor and ligand. Binding affinity is used to assess and rank the order of strengths of binding partner interactions, which is also measured by the equilibrium dissociation constant (Kd). Therefore, the higher the Kd value is, the lower the binding affinity of the ligand to its target site. The binding affinity between the two molecules is affected by noncovalent intermolecular interactions, such as hydrogen bonding, electrostatic interactions, hydrophobic interactions, and van der Waals forces, as well as the presence of other molecules.

The highest negative value of $\Delta \mathrm{G}$ with the lowest $\mathrm{Kd}$ value was found in the $\beta$ chain (domains $B$ and $E$ ) binding of fibrin (Figure 3) with the Subtilisin K2 enzyme (Table 1). The hydrolysis reaction is assumed to take place in the $\mathrm{E}$ domain where the catalytic triad residues (Asp19, His51, and Ser208) of the enzyme model interact with the E domain (Figure 3). Molecular docking analysis indicated that the three catalytic triad amino acid residues do not interact with other domains. This result suggested that no hydrolysis reactions occurred in

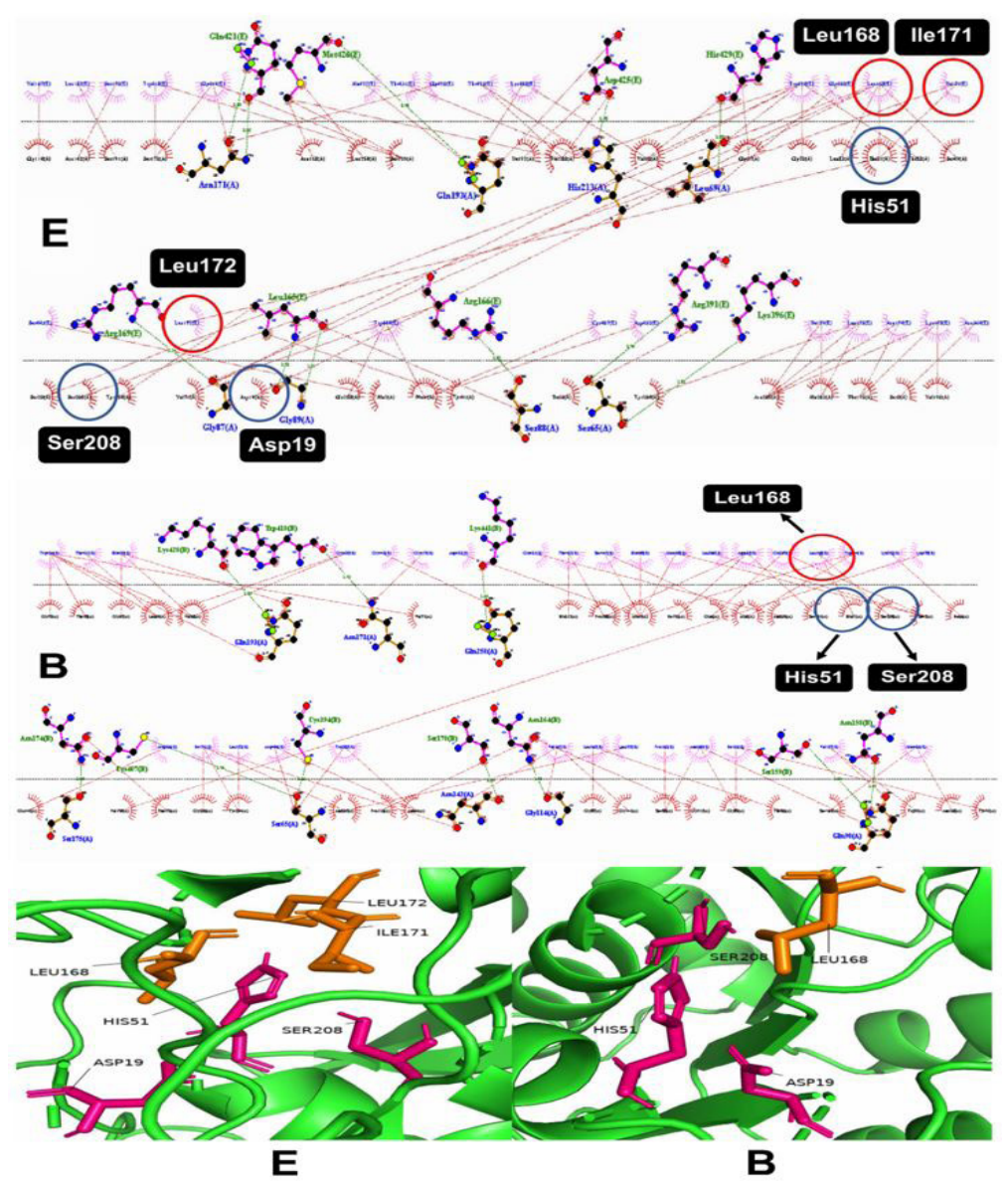

Figure 3. Interaction between the enzyme model with the beta chain of fibrin ( $\mathrm{E}$ and B domains) (blue circles and pink sticks = active site of the enzyme; red circles and sticks = substrate specificity of fibrin). 
the four domains because one of three catalytic triad amino acid residues in the enzyme (Asp19) did not interact with domains $\mathrm{A}, \mathrm{D}, \mathrm{C}$, and $\mathrm{F}$. The interaction of the $\mathrm{C}$ and $\mathrm{F}$ domains of the $\gamma$ chain of the fibrin molecule with the enzyme (Figure 4) showed the highest $\Delta \mathrm{G}$ (low affinity energy) and Kd values (Table 1), which means that the hydrophobic interactions and hydrogen bonds occurring between the enzyme and these two domains are much less favored than those of the other domains.

Hydrogen interactions can take place between the hydrogen of the - $\mathrm{OH}$ or the $-\mathrm{NH}$ group with oxygen or nitrogen. Hydrophobic interactions occur between aromatic rings or other hydrophobic moieties of the enzyme with hydrophobic side chains of the protein substrate (Kovalevsky et al., 2006; Bissantz et al., 2010). Docking results demonstrated that Asp19, His51, and Ser208 of the Subtilisin K2 active site interacts with Leu168, Ile171, and Leu172 of the E domain in the fibrin substrate, which might further drive the hydrolysis reaction.

In this study, hydrophobic interactions occurred more frequently between the enzyme (fibrin-degrading enzyme) and substrates (fibrin and fibrinogen) than hydrogen bonds. This might be because the enzyme and its substrate are large molecules, and the interactions that occur between two molecules are interface interactions. The LigPlot+ program has four numeric parameters related to the HBPLUS program and was used in calculating the potential hydrogen bonds and nonbonded contacts (such as hydrophobic interactions).

The two parameters define the hydrogen bonding and denote the maximum hydrogen-acceptor (H-A) and donor-acceptor (D-A) distances, and the default ranges of the maximum $\mathrm{H}-\mathrm{A}$ and $\mathrm{D}-\mathrm{A}$ distance values were calculated as $2.70 \AA \AA$ and $3.35 \AA$, respectively. An increase in these values means additional interactions. The next two parameters define the distance range of nonbonded contacts (such as contacts between atoms that are neither covalently bonded nor interacting via hydrogen bonds), and the default range of this contact distance value was 2.9-3.9.

The LigPlot+ analysis suggested that amino acid residues located at the active site of the fibrin-degrading enzyme (Ser208 and His51) interacted with amino acid residues of domains A (Ile154, Glu151, and Arg171) (Figure 2) and D (Ile154, Leu150, and Glu151) (Figure 2) on the fibrin substrate. The enzyme's active site was also suggested to interact with Leu168 of domain B (Figure 3). Residues from the $\mathrm{E}$ domain on the fibrin substrate that were implied to interact with the active site of the enzyme (Asp19, His51, and Ser208) were Leu168, Ile171, and Leu172 (Figure 3). Residues from domains C (Leu131 and Glu132) (Figure 4) and F (Leu131, Glu132, and Val128) (Figure 4) were suggested to interact with the active site of the enzyme.

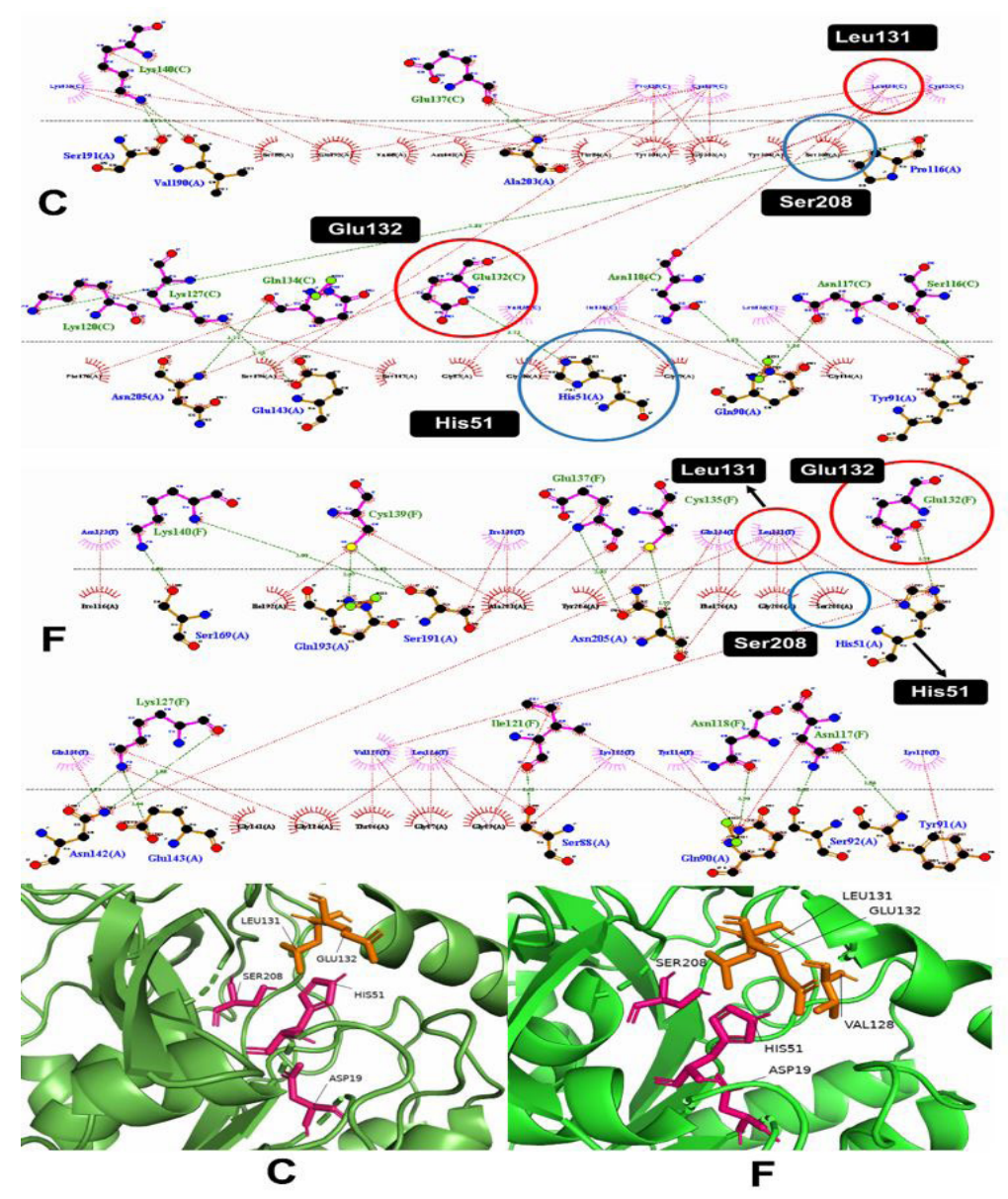

Figure 4. Interaction between the enzyme model with the gamma chain of fibrin ( $\mathrm{C}$ and $\mathrm{F}$ domains) (blue circles and pink sticks = active site of the enzyme; red circles and orange sticks = substrate specificity of fibrin). 
Fibrinogen is composed of two symmetric half molecules (dimers), and each dimer is composed of one assembly of three different polypeptide chains, namely, $\mathrm{A} \alpha, \mathrm{B} \beta$, and $\gamma$ chains (trimers) (Figure 1). The fibrinogen $\alpha$ - and $\beta$ chains are known to play an important role in thrombin-induced fibrin formation because fibrinopeptides $A$ and $B$ on the $\alpha$ - and $\beta$ chains are cleavage sites of $\alpha$-thrombin (Zhao et al., 2007). The fibrinogen $\gamma$ chain contains the main sites for the interaction with membrane receptors in platelets (Hawiger et al., 1982), where the aggregation process is mediated by the binding of fibrinogen to a platelet cell surface receptor, that is, glycoprotein IIb-IIIa (Farrell et al., 1992). The six peptide chains are held together by 29 disulfide bonds, and sulfhydryl groups are not contained in this fibrinogen chain. The half-cysteine residues are more concentrated in the three clusters along each chain (one N-terminal, one intermediate, and one C-terminal cluster) in the fibrinogen primary structure (Henschen et al., 1983; Herrick et al., 1999). Based on analysis using Prodigy (Vangone \& Bonvin, 2015; Xue et al. 2016), the interaction between the $\mathrm{B} \beta$ chain and Subtilisin $\mathrm{K} 2$ showed a more negative $\Delta \mathrm{G}$ value (high binding affinity) $(-15.6 \mathrm{kcal} / \mathrm{mol}$ ) and low Kd value (3.9E-12 M), followed by the $\gamma$ and A $\alpha$ chains.

The catalytic triad residues were not indicated in the docking between Subtilisin K2 and the three chains of fibrinogen (Figure 5, Figure 6). Interactions between the active site residues of the enzyme with residues of the fibrinogen chain $(A \alpha, B \beta$, and $\gamma$ chains) are implied. However, only the His51 and Ser208 residues of the enzyme's active site were suggested to interact with residues on the $A \alpha, B \beta$, and $\gamma$ chains, namely, Phe117 of the $\alpha$ chain, Trp125 and Leu121 of the $\beta$ chain, and Phe54, Asp53, and Thr57 of the $\gamma$ chain.

Based on the bioinformatic study, the interaction between the Subtilisin K2 enzyme and the E domain of the fibrin substrate showed $\Delta \mathrm{G}$ and $\mathrm{Kd}$ values 1.2 times greater and 0.0016 times lower than similar $\Delta \mathrm{G}$ and $\mathrm{Kd}$ values of the interaction between this enzyme and the $\mathrm{B} \beta$ fibrinogen chain, respectively. This implied that the Subtilisin K2 enzyme tends to interact more strongly with the fibrin substrate, and thus, this enzyme seems to act as a fibrin-degrading enzyme than as a fibrinogen-degrading enzyme, as the catalytic reaction was suggested to occur on domain $\mathrm{E}$ of the fibrin $\beta$ chain. Our earlier study showed the fibrin-degrading activity in the fibrin plate assay and fibrinogen-degrading activity in zymogram analysis (Syahbanu et al., 2020a, b). This bioinformatic study added information on the stronger interaction of the enzyme with fibrin than with fibrinogen at the molecular level. As previously mentioned, molecular and cellular interactions such as fibroblast proliferation and capillary tube formation occur in the $\beta$ chain, so the degradation of the $\beta$ chain by this enzyme (Subtilisin K2) can inhibit the occurrence of molecular and cellular interactions in its excessive action for individuals with disorders (Mosesson, 2005). In an in vitro study,

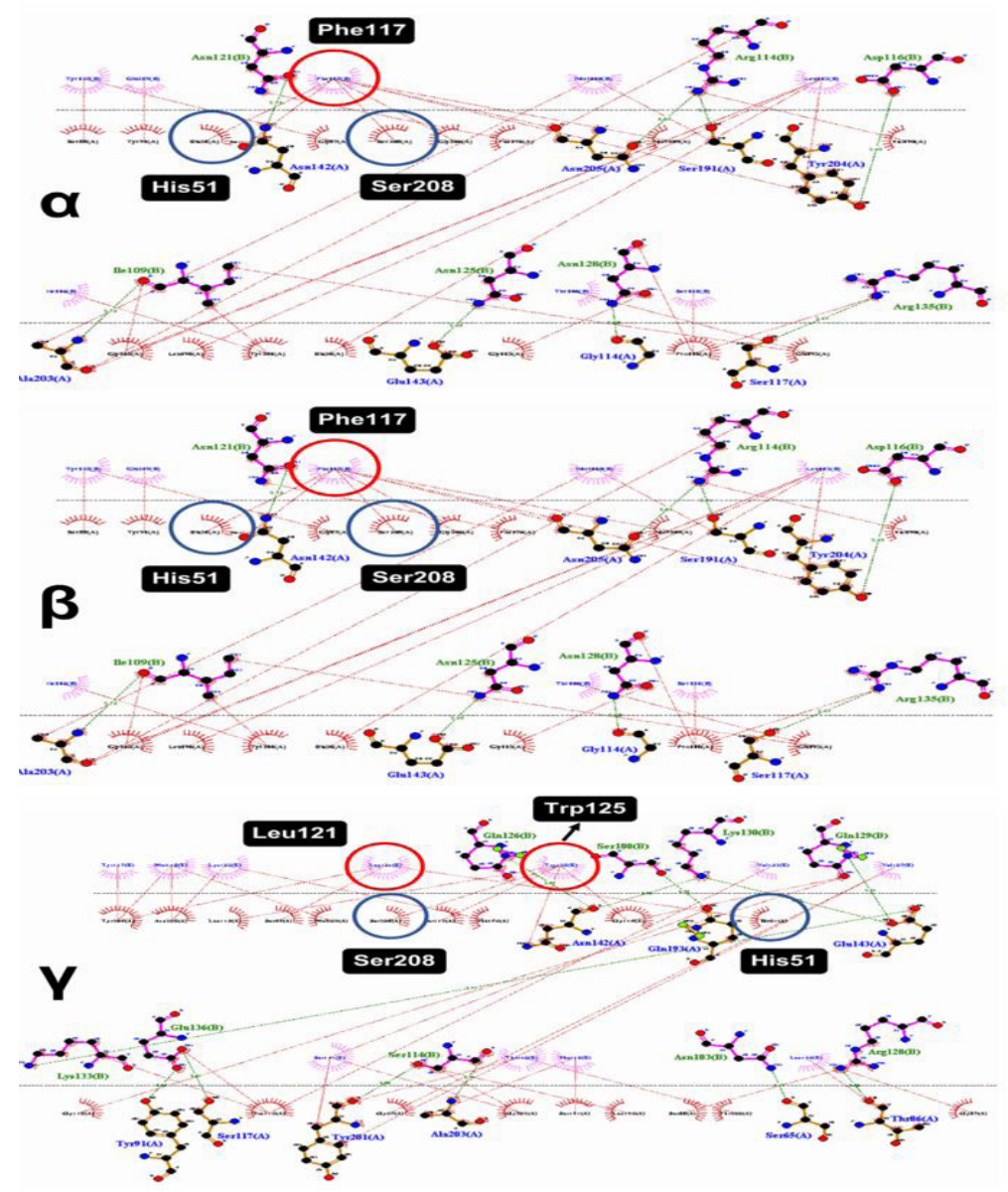

Figure 5. Interaction between enzyme model with the $\alpha, \beta$, and $\gamma$ chain of fibrinogen (blue circles = enzyme's active site; red circles = substrate residues that interacted with enzyme's active site). 


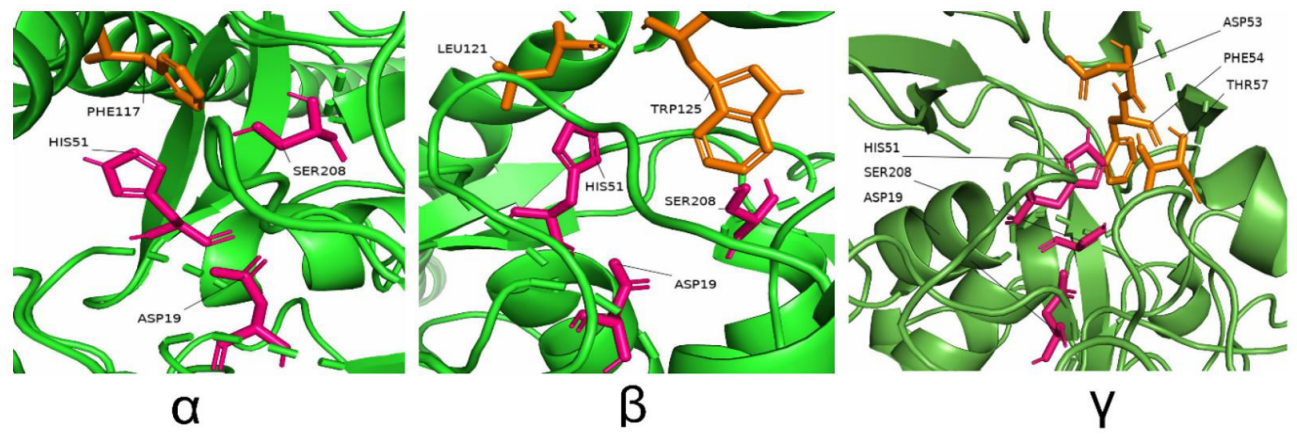

Figure 6. Interaction between enzyme model with the $\alpha, \beta$, and $\gamma$ chain of fibrinogen (pink sticks = enzyme's active site; orange sticks = substrate residues that interacted with enzyme's active site).

Fujita et al. (1995) reported that the cleavage of fibrin chains by nattokinase was 6 times more efficient than that of plasmin, but the cleavage of fibrinogen chains by nattokinase was only 3 times more efficient than that by plasmin, as measured with the $\mathrm{kcat}^{\mathrm{km}} \mathrm{km}^{-1}$ value. Thus, a nattokinase enzyme similar to our enzyme (Subtilisin K2) also appeared to be less active in fibrinogen hydrolysis but more active towards fibrin hydrolysis. Even though further molecular analyses at the atomic level are required, the present bioinformatic study is still important to reveal such a mechanism.

\section{Conclusion}

Molecular docking analysis showed that Subtilisin K2 and the substrates fibrinogen and fibrin use an extended binding pattern in their interactions with important residues to induce the enzymatic activity. Further analysis demonstrated that a hydrolysis reaction may occur between Subtilisin K2 and the E domain of fibrin. Asp19, His51, and Ser208, as Subtilisin K2's active site, were suggested to interact with Leu168, Ile171, and Leu172 of the fibrin substrate, which might have the potential to act with substrate specificity. There was no indications of a complete interaction between the catalytic triad residues of Subtilisin K2 and the three chains of fibrinogen. Therefore, it appears that Subtilisin K2 tends to act more as a fibrin-degrading enzyme than as a fibrinogen-degrading enzyme.

\section{Acknowledgements}

The author(s) received financial support for the research and/or publication from Master Program of Education Leading to Doctoral Degree for Excellent Graduates (PMDSU), Ministry of Research, Technology and Higher Education of the Republic of Indonesia (RISTEKDIKTI) [Grant No. 0045/E3/LL/2018].

\section{References}

Ariëns, R. A. S. (2013). Fibrin(ogen) and thrombotic disease. Journal of Thrombosis and Haemostasis, 11(Suppl. 1), 294-305. http://dx.doi. org/10.1111/jth.12229. PMid:23809133.

Arnold, K., Bordoli, L., Kopp, J., \& Schwede, T. (2006). The SWISSMODEL workspace: a web-based environment for protein structure homology modelling. Bioinformatics, 22(2), 195-201. http://dx.doi. org/10.1093/bioinformatics/bti770. PMid:16301204.

Benkert, P., Biasini, M., \& Schwede, T. (2011). Toward the estimation of the absolute quality of individual protein structure models.
Bioinformatics, 27(3), 343-350. http://dx.doi.org/10.1093/bioinformatics/ btq662. PMid:21134891.

Biasini, M., Bienert, S., Waterhouse, A., Arnold, K., Studer, G., Schmidt, T., Kiefer, F., Gallo Cassarino, T., Bertoni, M., Bordoli, L., \& Schwede, T. (2014). SWISS-MODEL: modelling protein tertiary and quaternary structure using evolutionary information. Nucleic Acids Research, 42(W1), 1-7. http://dx.doi.org/10.1093/nar/gku340. PMid:24782522.

Bissantz, C., Kuhn, B., \& Stahl, M. (2010). A medicinal chemist's guide to molecular interactions. Journal of Medicinal Chemistry, 53(14), 5061-5084. http://dx.doi.org/10.1021/jm100112j. PMid:20345171.

Bornikova, L., Peyvandi, F., Allen, G., Bernstein, J., \& Manco-Johnson, M. J. (2011). Fibrinogen replacement therapy for congenital fibrinogen deficiency. Journal of Thrombosis and Haemostasis, 9(9), 1687-1704. http://dx.doi.org/10.1111/j.1538-7836.2011.04424.x. PMid:21711446.

Computational Structural Biology Group. (2020). PRODIGY. Retrieved from https://bianca.science.uu.nl//prodigy/

De Moerloose, P., Boehlen, F., \& Neerman-Arbez, M. (2010). Fibrinogen and the risk of thrombosis. Seminars in Thrombosis and Hemostasis, 36(1), 7-17. http://dx.doi.org/10.1055/s-0030-1248720. PMid:20391292.

De Vries, S. J., \& Bonvin, A. M. J. J. (2011). Cport: a consensus interface predictor and its performance in prediction-driven docking with HADDOCK. PLoS One, 6(3), e17695. http://dx.doi.org/10.1371/ journal.pone.0017695. PMid:21464987.

European Molecular Biology Laboratory. (2020). LigPlot+ Version v.2.1. Retrieved from https://www.ebi.ac.uk/thorntonsrv/software/ LigPlus/install.html

Farrell, D. H., Thiagarajan, P., Chung, D. W., \& Davie, E. W. (1992). Role of fibrinogen $\alpha$ and $\gamma$ chain sites in platelet aggregation. Proceedings of the National Academy of Sciences of the United States of America, 89(22), 10729-10732. http://dx.doi.org/10.1073/pnas.89.22.10729. PMid:1438269.

Fujita, M., Ito, Y., Hong, K., \& Nishimuro, S. (1995). Characterization of nattokinase-degraded products from human fibrinogen or crosslinked fibrin. Fibrinolysis, 9(3), 157-164. http://dx.doi.org/10.1016/ S0268-9499(95)80005-0.

Geer, L. Y., Domrachev, M., Lipman, D. J., \& Bryant, S. H. (2002). CDART: Protein homology by domain architecture. Genome Research, 12(10), 1619-1623. http://dx.doi.org/10.1101/gr.278202. PMid:12368255.

Gorkun, O. V., Veklich, Y. I., Medved', L. V., Henschen, A. H., \& Weisel, J. W. (1994). Role of the aC domains of fibrin in clot formation. Biochemistry, 33(22), 6986-6997. http://dx.doi.org/10.1021/ bi00188a031. PMid:8204632.

Hawiger, J., Timmons, S., Kloczewiak, M., Strong, D. D., \& Doolittle, R. F. (1982). Gamma and alpha chains of human fibrinogen possess sites reactive with human platelet receptors. Proceedings of the National 
Academy of Sciences of the United States of America, 79(6), 20682071. http://dx.doi.org/10.1073/pnas.79.6.2068. PMid:6281794.

Henschen, A., Lottspeich, F., Kehl, M., \& Southan, C. (1983). Covalent structure of fibrinogen. Annals of the New York Academy of Sciences, 408(1), 28-43. http://dx.doi.org/10.1111/j.1749-6632.1983.tb23232.x. PMid:6575689.

Herrick, S., Blanc-Brude, O., Gray, A., \& Laurent, G. (1999). Molecules in focus fibrinogen. The International Journal of Biochemistry \& Cell Biology, 31(7), 741-746. http://dx.doi.org/10.1016/S13572725(99)00032-1. PMid:10467729.

Hill, M., \& Dolan, G. (2008). Diagnosis, clinical features and molecular assessment of the dysfibrinogenaemias. Haemophilia, 14(5), 889-897. http://dx.doi.org/10.1111/j.1365-2516.2008.01795.x. PMid:18564189.

Kastritis, P. L., Rodrigues, J. P. G. L. M., Folkers, G. E., Boelens, R., \& Bonvin, A. M. J. J. (2014). Proteins feel more than they see: Finetuning of binding affinity by properties of the non-interacting surface. Journal of Molecular Biology, 426(14), 2632-2652. http:// dx.doi.org/10.1016/j.jmb.2014.04.017. PMid:24768922.

Kovalevsky, A. Y., Liu, F., Leshchenko, S., Ghosh, A. K., Louis, J. M., Harrison, R. W., \& Weber, I. T. (2006). Ultra-high resolution crystal structure of HIV-1 protease mutant reveals two binding sites for clinical inhibitor TMC114. Journal of Molecular Biology, 363(1), 161173. http://dx.doi.org/10.1016/j.jmb.2006.08.007. PMid:16962136.

La Corte, A. L. C., Philippou, H., \& Ariëns, R. A. S. (2011). Role of fibrin structure in thrombosis and vascular disease. Advances in Protein Chemistry and Structural Biology, 83, 75-127. http://dx.doi. org/10.1016/B978-0-12-381262-9.00003-3. PMid:21570666.

Mosesson, M. W. (2005). Fibrinogen and fibrin structure and functions. Journal of Thrombosis and Haemostasis, 3(8), 1894-1904. http:// dx.doi.org/10.1111/j.1538-7836.2005.01365.x. PMid:16102057.

MyHits. (2020). Retrieved from https://myhits.isb-sib.ch/cgi-bin/ motif_scan

National Center for Biotechnology Information - NCBI. (2020). Retrieved from https://www.ncbi.nlm.nih.gov/Structure/lexington/ lexington.cgi

Research Collaboratory for Structural Bioinformatics - RCSB. (2020). Protein Data Bank (PDB). Retrieved from https://www.rcsb.org/

Schwede, T., Kopp, J., Guex, N., \& Peitsch, M. C. (2003). SWISSMODEL: An automated protein homology-modeling server. Nucleic Acids Research, 31(13), 3381-3385. http://dx.doi.org/10.1093/nar/ gkg520. PMid:12824332.

Sigrist, C. J. A., Cerutti, L., De Castro, E., Langendijk-Genevaux, P. S., Bulliard, V., Bairoch, A., \& Hulo, N. (2010). PROSITE, a protein domain database for functional characterization and annotation. Nucleic Acids Research, 38(Suppl. 1), 161-166. http://dx.doi.org/10.1093/ nar/gkp885. PMid:19858104.

Swiss Institute of Bioinformatics - SIB. (2020). Swiss-Model. Retrieved from https://swissmodel.expasy.org/

Syahbanu, F., Giriwono, P. E., Tjandrawinata, R. R., \& Suhartono, M. T. (2020b). Molecular analysis of fibrin degrading enzyme from Bacillus subtilis $\mathrm{K} 2$ isolated from indonesian fermented soybean moromi. Molecular Biology Reports, 47(11), 8553-8563. http://dx.doi. org/10.1007/s11033-020-05898-2. PMid:33111172.

Syahbanu, F., Kezia, E., Puera, N., Giriwono, P. E., Tjandrawinata, R. R., \& Suhartono, M. T. (2020a). Fibrinolytic bacteria of Indonesian fermented soybean: preliminary study on enzyme activity and protein profile. Food Science and Technology, 40(Suppl. 2), 458-465. http:// dx.doi.org/10.1590/fst.23919.

Tsurupa, G., Hantgan, R. R., Burton, R. A., Pechik, I., Tjandra, N., \& Medved, L. (2009). Structure, stability, and interaction of the fibrin(ogen) aC-domains. Biochemistry, 48(51), 12191-12201. http:// dx.doi.org/10.1021/bi901640e. PMid:19928926.

Utrecht University. (2020a). CPORT. Retrieved from https://milou. science.uu.nl/services/CPORT/

Utrecht University. (2020b). HADDOCK. Retrieved from https://milou. science.uu.nl/services/HADDOCK2.2/

Van Zundert, G. C. P., Rodrigues, J. P. G. L. M., Trellet, M., Schmitz, C., Kastritis, P. L., Karaca, E., Melquiond, A. S. J., Van Dijk, M., De Vries, S. J., \& Bonvin, A. M. J. J. (2016). The HADDOCK2.2 web server: user-friendly integrative modeling of biomolecular complexes. Journal of Molecular Biology, 428(4), 720-725. http:// dx.doi.org/10.1016/j.jmb.2015.09.014. PMid:26410586.

Vangone, A., \& Bonvin, A. M. J. J. (2015). Contacts-based prediction of binding affinity in protein-protein complexes. eLife, 4, e07454. http://dx.doi.org/10.7554/eLife.07454. PMid:26193119.

Wallace, A. C., Laskowski, R. A., \& Thornton, J. M. (1995). LIGPLOT: a program to generate schematic diagrams of protein-ligand interactions. Protein Engineering, 8(2), 127-134. http://dx.doi. org/10.1093/protein/8.2.127. PMid:7630882.

Wassenaar, T. A., Van Dijk, M., Loureiro-Ferreira, N., Van der Schot, G., de Vries, S. J., Schmitz, C., Van der Zwan, J., Boelens, R., Giachetti, A., Ferella, L., Rosato, A., Bertini, I., Hermann, T., Jonker, H. R. A., Bagaria, A., Jaravine, V., Guntert, P., Schwalbe, H., Vrannken, W. F., Doreleijers, J. F., Vriend, G., Vuister, G. W., Franke, D., Kikhney, A., Svergun, D. I., Fogh, R. H., Ionides, J., Laue, E. D., Spronk, C., Jurksa, S., Verlato, M., Badoer, S., Dal Pra, S., Mazzucato, M., Frizziero, E., \& Bonvin, A. M. J. J. (2012). WeNMR: structural biology on the grid. Journal of Grid Computing, 10(4), 743-767. http://dx.doi. org/10.1007/s10723-012-9246-Z.

Xue, L. C., Rodrigues, J. P., Kastritis, P. L., Bonvin, A. M. J. J., \& Vangone, A. (2016). PRODIGY: A web server for predicting the binding affinity of protein-protein complexes. Bioinformatics, 32(23), 3676-3678. http://dx.doi.org/10.1093/bioinformatics/btw514. PMid:27503228.

Yang, Z., Mochalkin, I., \& Doolittle, R. F. (2000). A model of fibrin formation based on crystal structures of fibrinogen and fibrin fragments complexed with synthetic peptides. Proceedings of the National Academy of Sciences of the United States of America, 97(26), 14156-14161. http://dx.doi.org/10.1073/pnas.97.26.14156. PMid:11121023.

Zhao, J., Pan, R., He, J., Liu, Y., Li, D. F., \& He, R. Q. (2007). Eisenia fetida protease-III-1 functions in both fibrinolysis and fibrogenesis. Journal of Biomedicine \& Biotechnology, 2007(5), 97654. http:// dx.doi.org/10.1155/2007/97654. PMid:17641727. 